УДК 811.161.1'42:821.161.1-3.09 Пильняк

Каневская Олъга,

кандидат педагогических наук, доцент, доцент кафедры русской филологии и зарубежной литературы Криворожский государственный педагогический университет

\title{
СПОСОБЫ ВЫРАЖЕНИЯ ОЦЕНКИ В АКСИОЛОГИЧЕСКОЙ КАРТИНЕ МИРА БОРИСА ПИЛЬНЯКА
}

\begin{abstract}
У статті охарактеризовано способи вираження оцінки в аксіологічній картині світу Бориса Пільняка. Під час дослідження було встановлено, що використання різноманітних способів вираження оцінки (оцінна лексика, оцінні словотвірні засоби, оцінні граматичні засоби, зображально-виражальні засоби) $е$ характерним для писъменника: оцінність забарвлюе всі рівні його художнъого мовлення, створюються оцінні мовленневі образи; за допомогою категорій оцінки та оцінності висвітлюються світобачення та світогляд автора, які відбиваютъся в його творчому методі та створюютъ ядро його аксіологічної картини світу.
\end{abstract}

Ключові слова: оцінка, оцінністъ, оцінна лексика, конотація, художній текст, авторсъкі інтениї̈, аксіологічна картина світу, Борис Пільняк.

Kanevska $O$. The methods for expressing assessment in the axiological picture of the world of Boris Pilnyak.

The article describes the ways of expressing the assessment in the axiological picture of the world of Boris Pilnyak - one of the most rationalist prose writers of the 20-30s of the XX century (V. Hoffman). During the study, it was found that the evaluation function is one of the most important in the language in general and in artistic speech in particular, because it expresses the speaker's attitude to any fact, event, phenomena, object. It helps to express the author's position in the texts and to reflect the author's value system. It was revealed that the use of various methods of expressing assessment (evaluative vocabulary, evaluative word-formation means, evaluative grammatical means, visual expressive means) is typical for B. Pilnyak: appraisal permeates all levels of his artistic speech; estimate verbal images are created; through the categories of assessment and appraisal, the author's worldview and worldview are expressed, reflected in his creative method and making up the core of his axiological picture of the world. Ontain an assessment and titles of B. Pilnyak's works. Most of the titles, being a way of expressing the author's modality, became allegorical images, images-symbols, and the author's interpretation of the text. There are also melioratives in the writer's texts that Express the speaker's positive attitude to reality, to the person and his actions. The Russian language's wordforming resources, which the writer uses skillfully, also contribute to the creation of evaluation in the text. Often emotional and expressive evaluation is expressed by means of diminutives. 
Key words: assessment, appraisal, evaluative vocabulary, connotation, literary text, author's intentions, axiological picture of the world, Boris Pilnyak.

Постановка проблемы. Борис Андреевич Пильняк (Вогау) (1894-1938) - выдающийся русский писатель, творивший в переломные послереволюционные годы XX века. Он был один из наиболее читаемых писателей в 20-30 годы. За недолгую жизнь Б. Пильняк успел написать романы («Голый год», «Волга впадает в Каспийское море», «Красное дерево», «Машины и волки», «Двойники», «Созревание плодов», «Соляной амбар»), повести («Повесть непогашенной луны», «Мать сыра-земля», «Заволчье», «Иван Москва», «Санкт-Питер-Бурх», «Его Величество Kneeb Piter Komondor» и др.), рассказы («Тысяча лет», «Ледоход», «Расплёснутое время», «Метель», «Без названия», «Старый сыр», «Синее море», «Жулики» и др.), очерки, пьесы, сценарии. Писатель вошёл в историю литературы как один из самых рационалистических прозаиков 20-30-х годов (В. Гофман [1]).

Борис Пильняк с первых шагов на литературном поприще привлёк внимание критиков и учёных. Творческая манера писателя, жанровая специфика его произведений, их тематика и проблематика изучались и критиковались Н. Ашукиным, А. Воронским, Г. Горбачёвым, М. Горьким, В. Гофманом, Е. Замятиным, И. Иоффе, Н. Катковым, А.Луначарским, Вяч. Полонским, Д. СвятополкаМирским, Л. Троцким, В. Ходасевичем, В. Шкловским и др. Зачастую произведения Пильняка оценивались поверхностно и исключительно по политическим параметрам. Так, Г. Горбачёв резко отзывался о произведениях писателя: «Пильняковщина <..> прежде всего бессюжетность» $[2$, с. 49].

Однако многие критики (Н. Ашукин, В. Гофман, С. Платонов и др.) положительно оценивали поиски новых форм и идей, смешение стилей и жанров, свойственные творческому методу писателя. «Отображение револючионной современности у Пильняка - не историческая эпопея, восстановленная по документам, а живой голос современника, ещё дъиащего этой историей, и лирические отступления автора, и его публичистические и исторические экскурсы, разрывающие ткань канонической художественной прозы, насыщены воздухом нашей великой эпохи, они современны, как психологические документы», писал Н. Ашукин [3, с. 61].

Анализ последних публикаций. В современном литературоведении наблюдаем возрождение интереса к творчеству и судьбе Бориса Пильняка, начавшееся в перестроечные годы и продолжающиеся 
сегодня - в XXI веке. Б. Б. Андроникашвили-Пильняк, К. Б. Андроникашвили-Пильняк， Л.Н. Анпилова， Г. Н. Воронцова， М. М. Голубков, С. Ю. Горинова, Е.Б. Дьячкова, И. В.Здерева, О. М. Кагирова, О. А. Казнина, А. С. Кацев, В. П. Крючков, М. Ю. Любимова, Н. Ю. Маликова, И. И. Профатило, В.П. Скобелев, Ю.Н. Тынянов, Т. Н. Фёдорова - вот далеко не полный список учёных, занимающихся поэтикой писателя. В пильняковедении исследуются многие вопросы, связанные с его творчеством: эстетическая и художественная системы, хронотоп, авторское сознание, авторские интенции, эволюция пильняковской прозы и её фольклорное начало, а также грани его творческой биографии (история создания произведений, этапы жизни, встречи с писателями и политиками, путешествия, неоконченные произведения, политическая травля писателя и т.д.). «На протяжении творческого пути Пильняк оставался верен себе и своим художественным приниипам, жанровые же метаморфозы в его творчестве тесно связаны со спецификой его писательского мышления, которое не только ясно чувствует потребности времени, но и способно выразить внутренний мир отдельной личности и иелой эпохи в процессе их самоопределения», - подводит промежуточный итог И. В. Здерева [4, с. 110-111]. Подчеркнём, что все исследователи отмечают несомненный талант писателя, своеобразность его творческой манеры, глубину художественного мира, жанрово-композиционное, стилистическое и языковое новаторство.

Орнаментальный стиль Б. Пильняка, жанровые поиски, его концепция мира и человека привлекали и западных славистов, таких как: И. Баги, Э. Дж. Браун, Г. Браунинг, Х. Гюнтер, А. Гуский, П. А. Дженсен, Д. Кассек, Р. Марш, М. А. Николас, Т. Ротшильд, М.Фальчиков и др. И этот интерес не случаен. Отметим, что произведения Бориса Пильняка начали переводиться уже в 20-е годы XX века. Так, роман «Голый год» впервые по-английски вышел в 1928 году в Нью-Йорке в переводе Алека Брауна с предисловием Георгия Соловейчика (Boris Pilnyak. The Naked Year. New York, 1928. Preface by George Soloveytchik). На основе анализа и интерпретации текстов писателя в западном пильняковедении были выявлены их жанрово-композиционные и стилистические особенности: амбивалентность, интертекстуальность, монтажность, принципы условности, многоплановости, неоконченности, характерные для модернизма. Например, А.Гуский в анализе романа «Волга впадает в Каспийское море» отмечает «чрезвычайное усиление семантической избирательности (чёрно-белое)» как одну из черт 
содержательно-композиционной структуры произведения [5, с. 501]. Д. Кассек указывает на амбивалентность структуры многих текстов Пильняка [6, с. 47]. Высоко оценивает творчество Б. Пильняка в целом и его роман «Голый год» М. Фальчиков, который, восхищаясь «размахом и острым чувством жизни среди смерти в этом романе», считает это произведение «началом какого-то нового жанра революиионной фантастики - смесъю гротеска с романтизмом», «шедевром», «эпосом револющии» [7, с. 33-34]. Исследователь замечает: писатель «хочет соединить историю общества со своей личной историей или же с историей героя подобного себе», «... в отличие от многих ровесников Пильняк не побоялся приняться за описание этой новой жизни, которая начала пробуждаться из хаоса» [7, с.34]. Таким образом, в западном литературоведении не только не угасает интерес к изучению творческого наследия Бориса Пильняка, но усиливается, особенно с появлением открытого доступа в архивы.

Существует ряд исследований (Т. М. Ауэр, Гопин Лю, Л.П.Григорьева, А. А. Грякалов, Н. Ю. Грякалова, Р. Ж. Гутьяр, И. Е. Карпенко, Л.Н. Костяева, Ю.Б. Орлицкий, И. О.Шайтанов и др.), в которых в разных аспектах исследуется язык произведений Б. Пильняка, а именно: средства художественной выразительности писателя, цветовая лексика, темы-символы, «человек пишущий», графичность прозы, авторская пунктуация, средства связи в контексте, особенности композиционного развёртывания текста и др. Однако, как видно из перечня тем исследований, остаются не решёнными многие вопросы, касающиеся идиостиля писателя, его словоупотребления, словесных образов, способов выражения авторской позиции в тексте, ономастического пространства, интертекстуальных связей и, конечно же, художественной картины мира автора в целом.

Итак, несмотря на несомненный интерес филологов к творчеству Б. Пильняка, остается широкое поле для исследовательской деятельности. Остаётся не изученной аксиологическая картина мира писателя, воплощённая в его произведениях.

Цель статьи - охарактеризовать способы выражения оценки в аксиологической картине мира Бориса Пильняка.

Материалом для исследования стали такие произведения Б. Пильняка, как: романы «Голый год», «Волга впадает в Каспийское море», повести «Мать сыра-земля», «Заволчье», «Расплёснутое время», «Повесть непогашенной луны», некоторые рассказы [8].

Изложение основного материала. Путь развития современной лингвистики антропоцентричный, т.е. направленный на человека 
и отталкивающийся от него. Именно поэтому на первый план выходит изучение языковой картины мира, в которой отражается общее национальное представление о мире в целом и о системе ценностей - понятий, связанных с идеалами и нормами общества, внешнего и внутреннего (ментального) мира, получившими положительную или отрицательную оценку членов общества, т.е. об аксиологической языковой картине мира. В.Н. Телия указывает, что «символь, получающие языковое воплощение», участвуют в организации «культурно-национальной системы критериев оченки, задающих антропометрическую точку зрения на обгект и точку его "размещения" на шкале оценок и создающих предпосылки для адекватного или, по крайней мере, понятного всем членам лингвокультурной общности вънесения "приговора" вещам и событиям»

Ценности «кодируются» с помощью включения оценочного значения в семантическое значение слова в системе языка. Поясняя этот процесс, В.Н. Телия пишет: «... эмотивно-оценочное отношение детерминировано мировоззрением народа - носителя языка, его культурно-историческим опытом, системой существующих в данном социуме критериев оценки...» [8, с. 39]. Таким образом, посредством оценочной лексики и лексики с коннотативно-оценочным компонентом значения отражаются ценностные идеалы, нормы, предпочтения и их противоположности (негативные их проявления - «антиидеалы») в аксиологической картине мира народа.

Заметим, что категории оценки и оценочности в языке связаны с лексическим значением слова как отражением объекта в системе языка (по этому поводу писали А. Д. Арутюнова, Н. Н. Болдырев, В. В. Иванов, Т. В. Маркелова, Л. А. Новиков, Е.Ф.Петрищева, Е. В. Рахилина, Л. А. Сергеева, А. А. Уфимцева, Н. М. Шанский, В. И. Шаховский и др.). В значении слова отражены и границы лексической сочетаемости, и предметно-логические связи, и свойственные данному слову эмоционально-экспрессивные свойства.

По мнению А.Д. Арутюновой, «оценивается то, что нужно (физически и духовно) человеку и человечеству» [10, с. 302]. Поэтому категория оценки всегда антропоцентрична, поскольку всегда отвечает природе человека.

Специфическим языковым выражением оценки обозначаемого является эмотивное значение стилистически маркированных лексических единиц, т.е. не являющихся стилистически нейтральными. Эмотивное значение слова рассматривается в прагматическом аспекте 
как отношение говорящих к словам, к тому, что они обозначают и каким образом воздействуют на слушающих.

Таким образом, оценочные категории характеризуют слово с разных точек зрения: во-первых, его положения на шкале ценностей: хорошо нейтрально - плохо (т.е. в оценке как в акте человеческого сознания заключается сравнение предметов, явлений и соотнесении их свойств и качеств с нормой); во-вторых, его эмоционально-экспрессивной окраски; в-третьих, репрезентации национально-культурной информации, представленной в национальной аксиологической картине мира.

Анализ текстов произведений Б.Пильяняка с точки зрения аксиологической картины мира позволил установить, что её выразителями стали оценочные слова и слова с эмотивным значением, частотные в текстах писателя.

Так, Б. Пильняк активно использует слова, семантика которых характеризуется оценочностью: мелиоративные (положительная оценка) и пейоративные (отрицательная оценка). С помощью этой лексики выражается соответствующее эмотивно-оценочное отношение говорящего (образа автора, персонажа) к адресату (персонажу, явлению, состоянию, понятию).

Частотно употребление пейоративов: детишечки, жулик, бездельник, негодяй, проныра, барынъка, глупыш, некрасивый, чуждый, враждебный и др. С их помощью выражается отрицательная (негативная) оценка персонажа, предмета, явления: неодобрение, порицание, ирония, презрение. В контекстах: ...она была очень некрасива, кривонога... [8, с. 278]; Дом был чужсд, враждебен. . . [8, с. 181]; Она была уродлива, суха [8, с. 458]; По улииам, по деревянным тротуарам шел дряхлъй, седой человек [8, с.39]; ...каждый приказчик, заведующий лавкой, кассир - жулик [8, с. 31].

Встречаются в текстах писателя и мелиоративы, выражающие положительное отношение говорящего к действительности, к человеку и его поступкам: замечателъный, чудесный, добродушный, весёлый, иеломудренно-чистый, обольстителъный и др. В контекстах: Мария Климовна, сухая старушка, она была чудесной женщиной, тем типом женщин, которые хранятся в России по весям вместе со старинными иконами Богоматерей [8, с. 116]; Вот на самом деле замечательная страна... [8, с. 15]; ... встречал их - хозяином высокий человек, бородатый, добродушный [8, с.88]; ...лесничий Антон Некульев, бодрый и весёлый человек... [8, с. 161]; .. они целомудренно-чисты, прямолинейны и строги [8, с.201]; ... Это била обольстительная женщина... [8, с. 241] и пр. С 
116 Літератури світу: поетика, ментальність і духовністъ. 2020. Bип. 14

помощью мелиоративов Борис Пильняк подчеркивает важность процесса написания литературного произведения: Каждая, каждая написанная наша строчка через столетие будет так же благоуханна, как та, которая написана столетъе тому назад [8, c. 255].

Оценочность в тексте создаётся и с помощью фразеологизмов, пословиц и поговорок, имеющих оценочное значение: чёрт возъми; шут его знает; бог с тобой; ... четвёртыье знали только по одной фразе, которая считалась пророческой и давала пророкам имена, например, - «жизнь человека сказка, гроб - коляска, ехать не тряско!»... [8, с. 109]; Иван, говоривший всегда про Ерёму, когда с ним заговаривали про Фому, всю дорогу рассказывал подробности перестрелки... [8, с. 32].

Д. Н. Шмелев указывал, что «Экспрессивно-оценочные элементы, закреплённые за словами, проявляются в процессе их сопоставления со словами, имеющими ту же предметную направленность» [11, с. 165]. Это же находим и у Б. Пильняка: Попов валялся (лежал) на диване, Гаврилов сидел у стола, и на коленях у него гомозилась (возилась) Наташка.. [8, с. 27]; ... жалования муж получает. . восемь рублей на своих харчах (питании) [8, с. 69]; ... послеобеденный сон скомкал (сократил) времл ... [8, с. 70].

Способствуют созданию оценочности в тексте и словообразовательные ресурсы русского языка, которыми писатель умело пользуется. Зачастую эмоционально-экспрессивная оценка выражается посредством деминутивов: умненъкая, серенъкий, детишечки, постелька, топорик, тарелочка, пузырёчек, волчонок; миленъкие женщины уменьшительно-ласкательная коннотация; народишко, ящичишко, людишечки, бородёнка, барынъка; низенъкий, маленъкий дом уничижительная, уменьшительно-пренебрежительная коннотация.

Оценочными являются также слова с увеличительноуничижительными суффиксами: стаканище, теснотища, домище и др.

Отношение к событиям или персонажам писатель выражает с помощью оценочной лексики, имеющей в своем составе отрицательные префиксы: недурная жена - положительная оценка; неинтересный материал, неважное событие, нехорошая болезнь, невесёлый век, негорбящийся человек - отрицательная оценка.

Отметим, что оценка выражается с помощью слов, относящихся к разным частям речи. В художественной речи Б. Пильняка частотны оценочные существительные и прилагательные (шутник, герой, 
трезвость, родство, братство, мудрость; плохой, горъкий, легендарный, геройский, хороший, прекрасный, чудесный и мн. др.). Например: Горъкая любовъ - дети [8, с. 21]; Жизнъ человека большая обязанность [8, с. 32]. Ярко оценка проявляется в формах степеней сравнения прилагательных: ... а мать-мать! единственнейшее, чудеснейшее, прекраснейшее - его матъ... [8, с. 135]; ... и тогда она поняла, что самое существенное в её поездке - убогое счастье бабы над рекой... [8, с. 32]; Наступило глубочайшее камынское лето [8, с. 488] - положительная оценка.

Свойственны художественной речи писателя и оценочные наречия разных семантических разрядов: качественные - хорошо, свежо, радостно (положительная оценка); Тогда он крикнул беспомощно, очень унизительно и жсалко [8, с. 134] (отрицательная оценка); сравнительно-уподобительные - по-волчъи, по-сучъи (отрицательная оценка); меры и степени - чуть-чуть, очень, весъма: Семъя, как всегда была...крепкой, чутъ-чуть холодной - отрицательная оценка. Она была оченъ красива и оченъ покойна - положительная оценка.

Встречаются в текстах и глаголы с оценочным значением, чаще всего с отрицательным: уничтожить, убить, струсить, корчить рожи, дипломатить, чудачествовать, жульничать, безмолвствовать; реже с положительным: заботиться, отогреть, вершить, покорять, одобрять и т.д.

Для того чтобы подчеркнуть какие-либо свойства, качества или признаки предмета Б. Пильняк активно использует разнообразные эпитеты с оценочным значением: Мир Валентины Александровны казался необыкновенным, небывалым и чрезвычайным [8, с.460]; Как много неизгяснимой сладости, задушевности и какой-то своеобразной чистой тоски чувствуется в каждом ударе колокола $[8$, с. 502] - положительная оценка; На него нападала тоска от лютого одиночества... [8, с.469]; Мороз в окнах казался холодным и nустым [8, с. 470] - отрицательная оценка.

Анализ показывает, что излюбленным тропом автора, выражающим оценку, является сравнение. Положительная оценка: У Андрея была красавича, прекрасная жена, дочь моряка, внучка моряка, - вольная, как море и как её отцы, обветренная всеми тримунтами [8, с. 42]; . . к нему пришла та правда, которая всё разводит, как пословица [8, с. 27]; За предпосылку, правильную, как аксиома, они брали правило... [8, с. 31]; Они гордъ своим делом, как философы [8, с. 137]. Отрицательная оценка: Была эта баба морщиниста, как старый гриб... [8, с. 30]; Мать рушится, как дом... [8, с. 24] - эти сравнения в портрете персонажа усиливают признаки старости. 
118Літератури світу: поетика, ментальність і духовність. 2020. Bип. 14

Эффективным способом выражения оценки в аксиологической картине мира писателя является метафора: И пока ползли колокола на канатах, они пели дремучим плачем... [8, с.111]; ... и было похоже, что дом прыгал в Волгу и разбил себе рожу - охренный дом - до крови красных кирпичей, да так и замер в своем скачке на дъбах, сдвинувшисъ, вжавшись в землю для прыжка [8, с.15]; Годь двадиать второй - четвертый много хранили в себе печали [8, с.20]; ...когда сумерки зеленоваты и когда сумерки воруют покой $[8$, с. 21] - отрицательная оценка явлений и объектов действительности. Примеры показывают, что с помощью метафоры автор создаёт импрессионистические, живые картины природы. Для многих метафорических значений характерен антропоморфизм: дом немотствовал, луна спешила, автомобили жрали лужи, залезало утро, усталость дня.

Содержат оценку и заглавия произведений Б. Пильняка. Большая часть заглавий, являясь способом выражения авторской модальности, стали аллегорическими образами, образами-символами, авторской интерпретацией текста: «Красное дерево», «Повесть непогашенной лунь», «Человеческий ветер», «Машины и волки», «Голый год», «Мать сыра-земля», «Заволчве»и др.

Когда писателем найдена форма для выражения слова, мы, читатели, открываем для себя содержание. О трудностях найти одно-единственное слово, которое точно бы выражала необходимое значение, содержало бы нужную оценку, соответствовало бы авторским интенциям, Б. Пильняк пишет в «Нерождённой повести»: «.. я хотел подыскать слово для луны, такое, которое ещё никем не сказано. - Круглая, зелёная, полная, - нет, не так, - сухая, подмороженная, ледяная. - Нет, не так, - безразличная, покойная, чёрствая, добрая, глупая, - нет, нет... луна как рубль... какое слово не придумай, - всё перебрали. Так я и не придумал слова для луны» [8, с. 88].

Выводы и перспективы исследования. Таким образом, в ходе проведенного анализа текстов произведений Бориса Пильняка было установлено, что использование разнообразных способов выражения оценки (оценочная лексика, оценочные словообразовательные средства, оценочные грамматические средства, изобразительновыразительные средства) характерно для писателя: во-первых, оценочность окрашивает все уровни его художественной речи; во-вторых, создаются оценочные словесные образы; в-третьих, посредством категорий оценки и оценочности выражаются мировидение 
и мировоззрение автора, отражающиеся и в его творческом методе, и составляющие ядро его аксиологической картины мира.

Перспективным направлением исследования, по нашему мнению, является описание аксиологической картины мира Б. Пильняка как составной части его художественной картины мира. Думается, что глубокое изучение поэтики его произведений в аксиологическом аспекте позволит не только более точно и адекватно интерпретировать тексты, но и охарактеризовать мировоззренческую концепцию писателя.

\section{Литература}

1. Гофман В. Место Пильняка // Мастера современной литературы. Борис Пильняк: Статьи и материалы; под ред. Б. В. Казанского, Ю. Н. Тынянова. Л. : Academia, 1928. С. 7-44. URL: https://imwerden.de/pdf/pilnyak_sttji_i_materialy_academia_1928 - text.pdf

2. Горбачев Г. Творческие пути Б. Пильняка // Борис Пильняк: Статьи и материалы; под ред. Б.В.Казанского, Ю. Н. Тынянова. Л. : Academia, 1928. С. 47-74. URL: https://imwerden.de/pdf/pilnyak_sttji_i_materialy_academia_1928_text.pdf

3. Борис Пильняк: опыт сегодняшнего прочтения. М. : «Наследие», 1995. $208 \mathrm{c}$.

4. Здерева И. В. Художественная эволюция прозы Бориса Пильняка 1930-х годов. Известия Саратовского университета. Т. 11. Серия: Филология. Журналистика. Вып. 3, 2011. С. 108-111. URL: https://www.sgu.ru/sites/default/files/journals/izvestiya/pdf/2013/12 $/ 13 / 23$ _sdereva.pdf

5. Guski A. Literatur und Produktion der sowjetischen Produktionsskizze und des sowjetischen Produktionsromans in der Zeit des 1. Funfjahrplanes (unveroff. Habilschrift), Berlin, 1986.

6. Кассек Д. Малоизвестный сценарий Бориса Пильняка или Игра в соцреализм // Борис Пильняк: опыт сегодняшнего прочтения. М. : «Наследие», 1995. С. 42-54.

7. Фальчиков М. Борис Пильняк глазами западного слависта // Борис Пильняк: опыт сегодняшнего прочтения. М. : «Наследие», 1995. C. 33-41.

8. Пильняк Б. Расплеснутое время: Романы, повести, рассказы. М. : Сов. писатель, 1990. 605 с. 
120Літератури світу: поетика, ментальність і духовністъ. 2020. Bип.14

9. Телия В.Н. Коннотативный аспект семантики номинативных единиц; Отв. ред. А. А. Уфимцева; АН СССР, Ин-т языкознания. М. : Наука, 1986. 141 c.

10. Арутюнова Н.Д. Язык и мир человека. М. : Языки русской культуры, 1999. $896 \mathrm{c.}$

11. Шмелев Д.Н. Современный русский язык. Лексика. М. : Просвещение, 1977. 372 с. 